\title{
The Effectiveness, Fairness and Consistency of Disciplinary Actions and Procedures within Malawi: The Case of the Civil Service
}

\author{
George Dzimbiri, \\ Lecturer in Management, University of Malawi; the Polytechtech P/Bag 303 Chichiri Blantyre 3 Malawi
}

\begin{abstract}
This paper analyses the effectiveness, fairness and consistency of disciplinary actions and procedures in the civil service of Malawi. The overall purpose of the study was to critically analyze the perceptions of civil servants regarding the effectiveness, fairness and consistency of disciplinary actions/procedure within the civil service.The study employed a qualitative research design by using both primary and secondary data collected from participants who were purposely selected. Skinners' reinforcement theories were adoptedto analyse the effectiveness and consistency of disciplinary actions and procedures in the civil service of Malawi. The results indicated that the theory is very relevant in the civil service as far as the aims of disciplinary procedurelactions are concerned. Hence, learning is the main aim of disciplinary procedurelactions, where employees learn the desirable behavior through reinforcement.The results also indicated that disciplinary procedure in the Civil Services faces a number of challenges. These among others include: lack of expediency, inconsistencies in handling disciplinary issues, failure to keep disciplinary records properly and favouritism. Similarly, the results also revealed that disciplinary procedure/ action was not effective. On the other hand, employees felt disciplinary procedure was not consistently applied, and that not all employees received the same treatment for similar actions. Therefore, the general view was that employees in the civil service are deprived of organizational justice due to weaknesses associated with the disciplinary procedurelaction in civil service. The study then recommends that leaders within the civil service receive guidance and appropriate training to correct this perception, hence leading to the consistent application of discipline and appropriate treatment of all employees.
\end{abstract}

Keywords: Effectiveness, Fairness, Consistence, Disciple, Disciplinary procedure, Disciplinary Actions, Civil Service, organizational justice

\section{Introduction}

Discipline is an action taken by management against an individual or group that fails to conform to the rules established by management within the organization(Grogan, 2009).Discipline is one of the most important elements in every organization. It is generally the backbone of every aspect of individual character because it guides how one speaks, behaves, responds to situations and treats others. Organizations are generally made up of groups of employees who are interdependent, and worktogether to achieve organizational goals. Thus, they interact with one another on a daily basis to fulfil their job-roles and to contribute effectively to their organizations. However, people enter the workplace with their own unique attitudes, abilities, values and perceptions, and this in itself can bring conflict in any organization (Robbins et al, 2003). To resolve conflict between individuals and groups, and to ensure a harmonious work environment, managers, supervisors and other leaders apply disciplinary action/ procedure to prevent escalation of bad behaviorsand to maintain industrial peace (Robbins et al, 2003). Disciplinary action, in its essence, is designed to correct behaviour and to maintain balance in the employment relationship (Grogan, 2009). When undesirable behaviour or actions are noticed in the workplace, it is thus the prerogative of leaders and managers to correct this behaviour and establish more acceptable norms or standards than those being corrected (Rao, 2009). Therefore, discipline and its subsequent rules and procedures form an integral part of the employment relationship between employer and employee.

The Civil Service of Malawi is the largest employer comprising people from different backgrounds with very different aspirations, beliefs, values and ambitions in life hence the prospects of these people breaking and keeping on breaking the rules and regulations is very high. Consequently, a comprehensive disciplinary procedurein the Malawi public Service Regulations was adopted in the civil service in order to ensurecompliance to terms and conditions of employment or to the codes of conduct by employees. To achieve effectiveness, the procedure has to be applied fairly and consistently, with proper procedures and policies being employed. The problem is that the civil service continues to witness a greater number of misconducts and noncompliance. This study, therefore, attempts to explain why there is an increase in misconducts and noncompliance in the civil service amidst comprehensive disciplinary procedure/ actions. Thus the study intends to 
evaluate the effectiveness and fairness of disciplinary procedure in the civil service. This paper proceeds in five parts. After this introduction, the second section discusses our conceptual framework by examining the concept of discipline andanalyzing disciplinary procedure, and their challenges. The third section examined the methodology used in this study. The fourth section presents results and suggests solutions and final section concludes the paper with recommendations.

\section{The Concept And Nature of Discipline}

The term "discipline" is a widely researched and complex phenomenon; consequently, there are numerous definitions of the concept.Dessler, (2004) views discipline as a procedure that corrects or punishes a subordinate because a rule or procedure has been violated.As for Byars and Rue (2009) discipline is viewed as an action taken against an employee when the employee has violated an organization's rule or when the employee's performance has deteriorated to the point where corrective action is needed.While Dessler, (2004) thinks of discipline as only applying to subordinates, Byars and Rue (2009) contend that discipline applies to every employee at the workplace. This is because even managers or the employers are employees of an organization in one way or another and need to be disciplined as well if discipline is to be seen to be applying equally to everyone in the organization.

On the other hand, Mathis and Jackson (2008) look at discipline as a form of training that enforces organization's rules. This definition by Mathis and Jackson tries to take away the thinking by many people who look at 'discipline' as something aimed at an individual for negative reasons or that the action is meant to make someone feel the pain.It has avoided labeling the term discipline a negative connotation so that it is received positively to whosoever is told to be well disciplined. This definition means that the way the person is instructed to behave after he or she has broken the regulations becomes a turning point in their conduct and they make sure to keep instructions, they get trained to behave well.

However, the commonality of all the definitions above is that they are not defining discipline as a field of study or endeavor but motivation to do or not to do something for the smooth running of the organization. The definitions above crown the term discipline as a process which all employees at a work place go through in order to make them understand and comply with the rules and regulations of the organization. This is to ensure that all procedures and standards of work are always observed. An organization is seen to be disciplining its employees when it makes the rules and regulations known to them, correct deviations by meting out punishments and appreciating or rewarding desired behaviour. All this goes back to the notion of training employees. They become trained because they change from the undesirable conduct to that which is desirable and part and parcel of the organization's terms and conditions of employment.

\subsection{Purpose of discipline}

There are many reasons why disciplinary action is taken on those that have gone on the wrong side of the law. According to Nova (2012) some would use disciplinary action to correct wrong behaviour while others would use it to humiliate the offenders and not train them. This is where they display a narrow thinking that disciplinary action is to be punitive; this gives a negative idea of the whole good purpose of it. Mostly, discipline serves as a learning process which gives employees experience and again forewarns would- beoffenders (Nova, 2012). To this end, there should not be any ambiguities associated with the various meanings of the term disciplinary action because it is just an action taken by the organization's management against an individual or group of individuals who have violated the rules and regulations of the organization.

As forMondy and Noe (2008: 522) disciplinary action is aimed at improving performance of the employee by ensuring that employee behaviour is consistent with the organization's goals. It is there to improve behaviour. It encourages employees to behave in a manner that makes them adhere to rules and regulations. Further, it also has to be there when one of the rules and regulations is violated. This concurs with Schermerhorn, (1996) who argues that discipline contributes to good behaviour of employees in an organization. In fact, indiscipline leads to poor performance and lower levels of productivity. Similarly, Van Der Bank et al (2007) assert that the role of discipline in the workplace is to ensure that individuals contribute efficiently and effectively to the goals of the organization. Production of goods and the provision of services would be impeded if, for example, employees were free to stay away from work when they please, to work at their own pace, to fight with their fellow employees or to disobey their employer's instructions. Hence it is the right and duty of employers to ensure that their employees adhere to reasonable standards of efficiency and conduct. Further,Cole (2006) adds that the advantages of organizations for a consistency disciplinary procedure are threefold; it contributes to the stability of the workforce, labour turnover is minimized and it promotes productivity.

Likewise,discipline helps employees improve their performance. In some cases, employees are unaware of behavior and actions that prevent them from achieving acceptable performance levels. The purpose of workplace discipline is to alert employees to their behavior and actions and help them understand how these inhibit performance and productivity (Grogan, 2009). As forGrote (2002) disciplinary action is an appropriate 
method for supervisors to use when correcting employees' misdeeds and helping them attain performance levels that meet employers' expectations. Hence workplace discipline is a teaching and improvement tool. In view of the above, we can deduce thatthe purpose of discipline is to correct behaviour. It is not designed to punish or embarrass an employee. Often, a positive approach may solve the problem without having to discipline. However, if unacceptable behaviour is a persistent problem or if the employee is involved in a misconduct that cannot be tolerated, for instance, theft, poor performance, insubordination; management may use discipline to correct the behavior

\subsection{Guidelines to Disciplinary Action}

This should happen after the organization has taken a deliberate effort to make the workers know or aware of which action or conduct constitutes misconduct or misbehavior. Firstly, managers have to do everything possible to avoid branding discipline a negative connotation, or something negative in nature. Secondly, disciplinary actions should as much as possible make somebody responsible enough and learn something for his or her own benefit and that of the organization. This means discipline has to be progressive.

Similarly, Costly (2007: 413) outlines a number of guidelines used by managers in undertaking disciplinary action. First, disciplinary action should be taken in private and that research has shown that holding a person up to public ridicule often has the opposite of the desired effect. Second, the offender's immediate supervisor must be the one applying the disciplinary action and that an application of a penalty should always carry with it a constructive element. Third, discipline should be handled in a constructive manner, aimed at the behaviour and not the person. Fourth, there should be that promptness. It is important that promptness is observed in the taking of disciplinary action, that is, it should promptly follow the undesired behaviour. If more time is taken after the misconduct is committed, the disciplinary action that comes later does not carry the real meaning of correcting the situation. Fifth, consistency is essential in the administration of disciplinary action. Sixth, there has to be some kind of rule of law. Nobody should be above the law and that if the same misconduct is committed by different people, the same disciplinary action should be meted on both equally without fear favour or prejudice. Seventh, disciplinary action should be the responsibility of the immediate supervisor. After the disciplinary action has been taken, the manager should attempt to assume a normal attitude towards the employee, and after the disciplinary action, the supervisor should help the employee to perform successfully on the job(Costly, 2007).

\subsection{Organizational Justice}

According toCropanzanoet al. (2007) and Latham (2007)organizational justice is the just and ethical treatment of individuals within an organization. In this case, organizational justice is a personal evaluation of the ethical and moral standing of managerial conduct. There are three dimensions oforganizational justice, namely distributive justice, procedural justice and interactional justice. Procedural justice deals with how an allocation decision is made whereas distributive justice refers to the fairness of the decision (Saunders and Thornhill, 2004). In this regard, procedural justice then relates to the fairness of the formal procedures required by the organization and its policy on the method of decision-making. A decision is fair if the outcomes are seen as balanced and correct, where balance refers to the fact that similar actions are taken in similar situations and correctness refers to the fact that the quality (that is consistency, accuracy, clarity, impartiality, procedural thoroughness and compatibility with ethical values) of the decision-making seems right (Stecher and Rosse, 2005; Thompson and Heron, 2005).

As argued by Thompson and Heron (2005),procedural justice is important for employee behaviour in that they are more likely to accept responsibilities if the related procedures are fair. Similarly, fair procedures also shape employee satisfaction with outcomes, in that they will more likely accept the outcomes if the procedures are fair than if they are not (Thompson and Heron, 2005). Lind and Tyler (2008) define objective procedural justice as an actual or factual justice, and subjective procedural justice as perceptions of objective procedures or to the capacity of an objective procedure to enhance fairness in judgements. However, Karnza and Fry (2008) define subjective perceptions of procedural justice by considering the cognitive, affective and behavioural components of the justice experience. The cognitive component refers to the calculations made by an individual regarding the objective fairness of a decision.

On the other hand, interactional justice refers to as the perceived fairness of the interpersonal treatment used to determine outcomes (Stecher andRosse, 2005). Interactional justice means the thoroughness of the information provided (that is, informational justice) as well as the amount of dignity and respect (i.e. interpersonal justice) demonstrated when presenting an undesirable outcome (Cropanzanoet al., 2007; Greenberg and Baron, 2007). For instance, when negative outcomes are presented in this manner, employees are more likely to accept the decision. But, when actions are consequently seen as interactionally unfair, employees are more likely to develop negative attitudes towards their supervisors (Charash and Spector, 2011). If 
employees feel as though they have been unfairly treated, they experience emotions such as anger and resentment (Pinder 2008).

\subsection{Common Disciplinary Problems}

According to Nova (2012) disciplinary problems can be described as those acts that are contrary to the rules and regulations of the work place. They can be caused or solved by either management or employees themselves. Similarly, Torrington et al, (2008:555) point out that 'a disciplinary problem is as likely to be solved by management action as it is likely to be solved by employee action. According to Torrington, (2008:605) some of the disciplinary problems faced in several workplaces among others include: First, negligence, which is defined as failure to do the job properly. This is different from incompetence because the assumption here is that the employee can do the job properly but has not; Second, unreliability, which is failure to attend to work as required, such as reporting late for work and absenteeism. Third, insubordination, this is refusal to obey an instruction or deliberate disrespect to someone in a position of authority. Fourth, interference with the rights of others, this covers a range of behaviours that are socially unacceptable. This involves fighting, which is clearly identifiable, harassment and intimidation which may be a bit difficult to establish. Fifth, theft, this is a clear- cut aspect of behaviour that is unacceptable especially when it is from an employee and lastly, safety offences. These are aspects of behaviour that can cause accidents or hazards.

\subsection{Disciplinary Procedure}

According toScott (2011) a disciplinary procedure is a step by step technique that is followed in an event when an employee has violated the standards of performance or behaviour. In this regard, a disciplinary procedure is one of the stages in a disciplinary process. The steps indicate the sanctions to be applied with due consideration of the offence committed and the employee committing that offence. Similarly, Nova (2012:813) argues that disciplinary procedures set out the stages through which any disciplinary action should proceed. The procedure provides an acceptable mechanism within which management may exercise control over employees when their performance or behaviour does not reach the required standards (Dzimbiri, 2009:37). To be deemed fair, disciplinary procedures should be used consistently and have uniform standards in the approach to disciplining employees. This helps avoid confusion and possible legal implications caused by inconsistent and sometimes harsh disciplinary decisions that are deemed unfair and unjust. Similarly, Stone (2005:22) argues that an inconsistent and unplanned approach to imposing discipline leads to legal action being taken against the organization. Additionally, Armstrong (2010) contends that a disciplinary action should not be taken against an employee unless the following conditions are met: First, it is undertaken only in cases where good reason and clear evidence exists. Second, it is appropriate to the nature of the offence that has been committed. Third, it is demonstrably fair and consistent with previous action in similar circumstances. Fourth, it takes place only when employees are aware of the standards that are expected of them or the rules with which they are required to conform. Fifth, employees are allowed the right to be represented by a representative or colleague during any formal proceedings. Sixth, employees are allowed the right to know exactly what charges are being made against them and to respond to those charges. Lastly, employees are allowed the right of appeal against any disciplinary action (Armstrong, 2010).

Armstrong (2010) presents a general disciplinary procedure from which organizations can draw theirs from. It begins with the informal warning which is given to the employee in the first instance or instances of minor offences. This warning is administered by the employee's immediate supervisor. Secondly, a formal written warning letter is given to the employee in the first instance of a serious offence or after repeated instances of minor offences. Then further disciplinary action is given to an employee if, despite previous warnings, he or she still fails to reach the required standards in a reasonable period of time. This disciplinary action could be dismissal. Additionally, an employee can be summarily dismissed only in the event of gross misconduct as defined in the company rules (Armstrong, 2010)

For the purpose of this study, Reinforcement theories by Skinner form the theoretical framework for this study. The theory was adopted due to its relative importance to the phenomenon understudy and can help in explaining the subject matter.The reinforcement theories of Skinner provide a technical description and application of discipline (Werner, 2007). According to these theories, learning needs to take place before desired behaviour can occur. Instrumental learning is defined as a situation where behaviour is influenced by the consequences thereof. According to Werner (2007), positive reinforcement, negative reinforcement and punishment are examples of this learning process. As forKreitner and Kinicki (2007), positive reinforcement would constitute the consistent presentation of something desirable (for instance, recognition). On the other hand, negative reinforcement is defined as the reinforcement of behaviour that reduces negative situations (for example, shouting at someone where the shouting only stops after compliance). In view of this, punishment involves an undesirable action towards a person, for example stopping the salary of an absent worker.In this regard,managers in the public sectorsare advised to make use of different forms of discipline. Warnings (i.e. 
verbal, written and final written), suspensions (with or without remuneration), transfers, demotion and dismissal are some of the options mentioned(Grossett, 1999). The principle of progressive discipline is applied when these options are chosen according to the seriousness of the offence. Gomez-Mejia et al (2005) describe positive discipline, where counselling sessions between the employee and supervisor replace punishment actions. Counselling skills would, however, be required for the successful implementation of this option.

\subsection{Challenges of Discipline}

There are a number of challenges associated with discipline (Cropanzano et al, 2007;Rao, 2009;Bendix, 2010 and Grote, 2007). First, workers are unhappy, managers spend time on each disciplinary case, interpersonal relationships between managers and employees suffer and eventually the overall productivity of the company drops(Cropanzano et al, 2007). Since this method mainly focuses on the use of penalties or threats thereof, what it does is forcing the workers to leave up to the expectations of the company. Secondly, the use of punishments and penalties may cause anger, apathy, resentment and frustration on the workers side and severely affect production(Rao, 2009). Third, the penalty-driven disciplinary system usually makes the manager a 'bad guy'. Most Managers are reluctant to punish workers because it makes them feel like they are wrong. Instead they tend to wait until a small behavior turns into a crisis. Fourth, workers on the other hand see punishment as personal attack, the manager as a dispenser of punishment and therefore stop communicating with superiors(Rao, 2009).Fifth, progressive discipline only generates compliance not commitment (Bendix, 2010).Effective discipline should come from self-discipline, in which a person changes and reinforces his own behavior without much external influence(Grote, 2007). If an employee chooses not to change his/her behavior, no matter what punishment is, he will continue to do so.

\section{Research design and method}

\section{Methodology}

The study adopted a qualitative research approach. The research design is suitable for generating data that would facilitate understanding of the experiences that employees have on disciplinary procedures. Population and sampling: The participants in the study were purposively selected. The participants included employees who have experienced the disciplinary procedure practiced in the public service. Other participants were experts in the disciplinary procedure namely, representatives of trade unions, industrial relations managers, human resources managers. The senior staffs were sampled using the cluster sampling. The rationale for cluster sampling was to ensure that the opinions of the key rank structures are recorded, bearing in mind that these have significant class biases regarding employee disciplinary actions.

Both primary data particularly interviews and secondary data sources were used as data collecting methods.Interviews were conducted with thirty (30) employees among whompersonnel from the Ministry of Agriculture and Food Security were included. Some members from the Appointment and Disciplinary Committee were also visited at the Ministry for it was hoped that they were at the centre of all the disciplinary cases and could provide the necessary information. This method allowed for an in- depth data collection as the information sought was supplemented through probing. On the other hand, documentary sources were also used.The information was basically collected from the personal files of those officers who were once disciplined.

Data analysis

Qualitative or content analysis and quantitative or average analysis techniques was used to analyze the gathered data. The content analysis method was used in order to analyze narrative data and derive meaning from them while the average analysis method was used for quantitative data to come up with frequency distribution from responses. These were used because the study was purely descriptive on the basis of field notes and they were manually analyzed.

Ethical considerations: When carrying out any research study, researchers are strongly advised to follow ethical considerations (De Vos, 2008). This study therefore, observed the following ethical considerations. Firstly, informed consent was obtained from the participants by means of a letter communicating the essential information pertaining to the research. Secondly, time was allocated for debriefing at the end of each research interview. This was done to minimize any harmful effects of their participation in the study. Thirdly, confidentiality was maintained at all times and participants were informed of the rationale and recording and the safekeeping of the interviews. It should be noted that participation was voluntary.

Ensuring reliable data

The researcher employed certain strategies to ensure trustworthiness of data. In this regard, Guba's (Babbie and Mouton, 2001) method was applied in order to achieve credibility, transferability, dependability and confirmability. Trustworthiness was achieved by prolonged engagement, triangulation, peer debriefing, purposive sampling, reflection, phenomenological interviews, structural congruence, authority of the researcher and compact description (Babbie and Mouton 2001; Cresswell, 2003). 


\section{Results}

Thissectionpresents and discusses data on effectiveness, consistency and fairness of disciplinary procedure in the civil sector of Malawi. Itbegins by presenting and outlining the research findings as well as analyzing data in accordance with the study objective. The sectionpresents key findings based on the objective of the study. A total of thirty employees were interviewed from different government institutions in order to examine the fairness, consistency and effectiveness of the disciplinary procedures that are followed in the civil service.

\section{(a) Disciplinary Problems in the Civil Service.}

This section sought the views of the respondents pertaining to disciplinary problems in the civil service.The respondents were asked to identify the most common disciplinary problems in the civil service. They cited absenteeism, theft, insubordination, dishonest, drunkardnesswhile on duty,dishonest, supervisory weakness, lack of motivation, weaknesses of disciplinary measures, job dissatisfaction and frustration from work related issues.The Malawi Public Service Regulations (MPSR) (1983) also outlines several common disciplinary problems faced in the Civil Service. These among others include: absenteeism, negligent performance of duties, display of insubordination by word or conduct, habitually taking liquor or habit- forming drugs to excess, failure to take reasonable care of any government property in his or her custody or on charge to him, bribery, and theft by false pretence or forgery (MPSR, 1983).

First, most respondents agreed heavily on absenteeism as one of the biggest setbacks in the civil service. This absenteeism usually occurs without leave or without giving any valid excuse at all. Second, negligence is another disciplinary problem. They explained that most of the civil servants are not committed to their work in that they do not do their work whole heartedly. Government loses a lot of money through employee's negligence in the performance of their duties. Third, theft by public servants also happens to be a disciplinary problem. When an employee steals from the workplace disciplinary action follows immediately.

Fourth, lack of motivation in their job is another disciplinary problem. This hinders them to take an extra mile in how they perform their duties. They further explained that motivation is equal to having incentives, which are not always there in government and if any, they are given to a few people especially bosses hence a source of disciplinary problem. Consequently,frustrations and job dissatisfaction arise. These frustrations ranged from lack of recognition of best performers in the civil service to long stay on one post without getting promoted. All are paid for filling the vacancy and not because of performance. This demotivates most of the employees and they get themselves engaged in other acts of misconduct because of frustrations. Similarly,job dissatisfaction happens because they may want to make ends meet by doing businesses during working hours to have more money. They may also steal from the office to sell the stolen items and many more money. Fifth, supervisory weakness or laxity on the part of supervisors when it comes to upholding the rules and regulations of the workplace is another disciplinary problem. The majority of the respondents lamented that most often the bosses are on the fore front breaking the rules, which makes juniors follow suit because they are sure there will be nobody to reprimand them. However, the reason could be that not many of the employees, including the supervisors, are aware of the terms and conditions of employment hence those happen due to ignorance of the expected code of conduct.

The findings in this section revealed that there are a number of disciplinary problems in the public service. They include:absenteeism, theft, insubordination, dishonest, drunkardnesswhile on duty,dishonest, supervisory weakness, lack of motivation, weaknesses of disciplinary measures, job dissatisfaction and frustration from work related issues. These disciplinary problems are also noted in the literature.The MPSR (1983) also outlines several common disciplinary problems faced in the civil service. These among others include: absenteeism, negligent performance of duties, display of insubordination by word or conduct, habitually taking liquor or habit- forming drugs to excess, failure to take reasonable care of any government property in his or her custody or on charge to him, bribery, and theft by false pretense, forgery (MPSR, 1983). Similarly, Torrington (2007) also highlighted negligence, insubordination, poor performance, unreliability and theft as the causes of disciplinary problems. This can be deduced that disciplinary problems in the findings concur with those in the literature.

\section{(b) Disciplinary Procedures followed in the Civil Service.}

This section sought the views of the respondents concerning the disciplinary procedure used in the civil service.Generally, all respondents gave out the procedure that is followed in government. The first step in the procedure is that of giving the law offender a verbal warning. They cited the verbal warning involves a superior making a statement to a subordinate regarding what he has done wrongly, how to correct such behaviour and what will happen if the misconduct continues. The second step is written warning. This is a statement given to 
an employee by a superior, when an act of misconduct has been committed. This usually comes after the verbal one. They said that this sets records in the personal file for future reference. It becomes more valid when an employee acknowledges receipt of the warning letter.

On the other hand,personal files were visited to appreciate how some members of staff were at one time disciplined and the procedure that was followed to arrive at the final decision. It was discovered that most of the cases were never finalized. All that was seen in most of the files were first warning letters and never any more letters. This may mean two things. It is either the employees changed completely for the better or the weakness of the procedure and that first warning letter expired and could not attract the second warning letter.

Theprocedure followed in the civil service to some extent concurs with the one in theliterature and to a certain extent, it seems no to be in agreement with the findings of the study.According to Armstrong (2010) a general disciplinary procedure begins with the informal warning which is given to the employee in the first instance or instances of minor offences. This warning is administered by the employee's immediate supervisor. Secondly, a formal written warning letter is given to the employee in the first instance of a serious offence or after repeated instances of minor offences. Then further, disciplinary action is given to an employee if, despite previous warnings, he or she still fails to reach the required standards in a reasonable period of time (Armstrong, 2010). In view of this, the literature stresses that the warnings are to be given by the immediate supervisor of that particular officer. But that is not the case in government. All the warnings, starting from the verbal one to the written ones are done by the human resource officers. The immediate supervisors take the offending officer to the office of the human resource officer so they can warn him or her whichever way. This removes the spirit of responsibility of the action taken on the offending officer. The human resources office is there just to reprimand people and not do other activities like the maintenance or strategic activities.

On promptness of handling cases, Costly (2007) differs completely with what happens in government. He contends that disciplinary cases should be handled with promptness. This is the timeliness that is required to settle disciplinary cases so that they carry with them the meaning the action is for. But looking at what happens in the civil service, it is almost impossible for government officers to settle the cases they have in time due to bureaucracy.

\section{(c) Effectiveness, consistency and fairness of the Procedure.}

This section sought the views of the respondents pertaining to effectiveness, consistency and fairness of the disciplinary procedure. There were different views on how they perceive the functionality of the disciplinary procedures followed in the civil service. Most of the respondents conceived that the procedure is not effective, consistent and fair while the other minority held a contrary view. They conceded that the procedure is too long, meaning; it takes time for a decision to be made on a particular case because there are a lot of things to be fulfilled for a supervisor to meet an action to the offender. They also revealed that there are huge practices of biasness associated with the procedure in that only employees loyal to the government of the day are not subjected to disciplinary actions. The procedure is also usually politicized as it is used as witch-hunt for employees who are supporters of the opposition parties. Further, they revealed that the requirement of giving the second warning letter if the officer commits another offence within six consecutive months defeats the whole purpose of meeting disciplinary measures on offenders.

On the contrary, very few respondents feltthe disciplinary procedure is effective because it gives room or chance to the offender to make an improvement in his or her conduct. Further, they also felt that the procedure is fair and consistent because regardless of employees' ranks, everyone goes through the same process. Similarly, they conceived that it allows them to be given chance to be heard. To them, this is a rule of natural justice where a person has to be heard first before a verdict is made on them.

The literature agrees with the findings in terms of the importance of the disciplinary procedure that is followed in the civil service. It agrees that the procedure allows for investigations to take place and that there is fairness and justice in the handling of the case because the offending officer is given chance to be heard (Torrington, 2007). Apart from that, it gives people a second chance to improve on their behavior (Nova, 2012). However, as per Dzimbiri (2009) the disciplinary procedure is too long and takes time to resolve issues and ends up piling on the desks without being attended to. Hence, the findings of the study concur with the literature. On the other hand, the fact that the majority revealed that the disciplinary procedures/action are not consistent and fairness in their application in the civil service, implies that there is no organizational justice in the civil service because a decision is deemed to be fair and consistent if the outcomes are seen as balanced and correct (Stecher and Rosse, 2005; Thompson and Heron, 2005). And yet those of the civil service lack the same characteristics hence they create organizational injustice.

(d) Challenges of the Disciplinary Procedures followed in the Civil Service. 
This section sought the views of the respondents on the challenges associated with disciplinary procedure. The majority cited delays, loss of meaningfulness of the disciplinary action, lack of skills on the part of supervisors, employee over protection, failure to keep records of disciplinary actions.

Firstly, delays in dealing with disciplinary issues or to sort them out are another challenge. It says most cases should be dealt with in a matter of weeks. Yet in government, a decision to discipline offenders may come after six or seven months. Some have even received their dismissal letters after one or two years. This comes in as a shock because by the time they receive this information, they might have forgotten of the offence they committed and may be they started improving in the way they conduct themselves. The disciplinary action loses its meaning because of lack of expediency. Secondly, immediate supervisors are seen not to be strong enough. This is because warning letters are given expirydates for them to still be effective. For instance, nowadays a warning letter is valid until six months for it to be counted as the second or third valid letter to warrant a disciplinary action. If an employee behaves well for six months and repeats misconduct in the seventh month, a fresh first warning letter is issued. This brings compromised work output or standards because management is seen to be failing to control the bad happenings at the workplace.Thirdly, at Commission level, there are case workloads because they handle all cases from the whole civil service because of the procedures that are in place. This makes it difficult to resolve cases timely and most of the times some cases are never handled at all, making employees feel they are insulated.Thirdly, failure to keep clear records of the whole disciplinary process was another challenge. This is mostly because of the handovers that happen from the controlling officer to the chairperson of either the Civil Service Commission (CSC) or Appointments and Disciplinary Committee (ADC). The moment the handovers are done, all the controlling officers wait for is the feedback from up there. They rarely bother to keep track of records since the case is handled at another level. It becomes a challenge when more information is required to substantiate the claims leveled against the offender.

The findings above revealed that the following were the challenges associated with disciplinary procedures in the civil service of Malawi: delays, poor record management, and loss of meaningfulness of the disciplinary action andfavoritism or biasness. Most of the findings concur with the literature as it stipulates that poor record management, delays and lack of meaningfulness of the disciplinary actions, favoritism and biasness among others are the challenges associated with disciplinary procedures (Thompson and Heron, 2005; Greenberg and Baron, 2007 and Funermore, 2006). However, there are some peculiarities in the findings that are not found in the literature. For instance, employees' feeling of overprotected, and supervisor's lack of strength pertaining to disciplinary process. This can be deduced that the literature is not exhaustive as far as the challenges associated with disciplinary procedures are concerned.

It is worth noting that the fascinating issue in this study is that looking at the whole essence of disciplinary procedure/actions; it appears to apply to Skinners' reinforcement theories. That is, there is an element of learning. In this case, disciplinary procedure/actions are there for employees to learn good behaviors and reduce bad behavior that cannot contribute to the achievement of organizational goals. Skinner contends that positive reinforcement, negative reinforcement and punishments are examples of the learning process (Werner, 2007). He further contends that negative reinforcement is the reinforcement that reduces negative situation (Werner, 2007). In this study, it was found out that disciplinary procedure/ action is used to correct wrong behavior. Similarly, it was also revealed that disciplinary action/procedure serves as a learning process which gives employees experience and again forewarns would- be- offenders.

In view of this, it can be deduced that Skinners reinforcement theories are much relevant in the civil service as far the aims of disciplinary procedure/ actions are concerned. However, in terms of how the procedure is applied in the civil service leaves a lot to be desired. Effective negative reinforcement is supposed to be applied correctly, fairly and consistently in order to bring the desired behavior, unfortunately, that is not the case with the civil service. The findings showed that it is not effective, consistent and fair because it is associated with many obstacles which among others include; favoritism, politics and slowness in terms of solving disciplinary cases. In view of this, a conclusion can be made that there is no organizational justice in the civil service due to ineffectiveness, inconsistency and unfairness of the disciplinary actions/ procedure followed in the civil service.

\section{Conclusion And Recommendations}

The study has evaluated the effectiveness, consistency and fairness of disciplinary procedure/action in the civil service. The findings of the study indicate that the disciplinary procedure/action in the civil service is not effective, consistent and fair.The measure of fairness of disciplinary procedures could be used as an important tool to manage discipline in organizations. This study has shown that employees experience the disciplinary procedure of the civil service as traumatic and emotionally exhausting. It can also be concluded that employees experience the disciplinary procedure as unfair. It is the manner in which discipline is applied and the different role players that are involved in the disciplinary procedure, in particular, that make it a lengthy and time-consuming process. The disciplinary procedure causes unnecessary strain and pressure on employees, 
mostly due to delays in finalizing cases. Hence bring in organizational injustice. The study then has recommended that three components are necessary for the effective maintenance of a disciplinary procedure in an organization. The components include consultation or negotiation, communication with everybody concerned regarding the exact way in which the system operates, and training of the individuals involved in a disciplinary process. Similarly, the application of discipline should be immediate, with warning, consistent and impersonal. Likewise, the roles of the CSC and ADC in the handling of disciplinary cases have to be decentralized. This means the powers to issue penalties to offenders should also be given to the human resources personnel at work station level so that these issues should be resolved expediently. This will help ease the workload which is there and again those officers at CSC and ADC could be put to better use in the civil service other than just wait for cases from other office.

\section{References}

[1] Armstrong, M. (2010) A Handbook of Human Resource Management Practice, $2^{\text {nd }}$ Edition, New York; Kogan Page Limited (US)

[2] Babbie, E. \& Mouton, J. (2001). The practice of social research. Cape Town: Oxford.

[3] Byars and Rue M (2009). Reward Management: A handbook of remuneration strategy and practice (5 $5^{\text {th }}$ ed.). London; Kogan Page

[4] Costly, D. C. and Todd, R. (2007) Human Relations in Organizations; $3^{\text {rd }}$ Edition. New York: West Publishing Company.

[5] Cohen-Charash, Y. \& Spector, P.E. (2011). The role of justice in organizations: a meta-analysis.

[6] Organizational Behavior and Human Decision Processes, 86(2), 278-321.

[7] Cresswell, J.W. (2003). Research design: qualitative, quantitative and mixed methods approaches. Thousand Oaks, CA: Sage.

[8] CropanzanoR.and Mitchell M.S., (2005). Social Exchange Theory: An Interdisciplinary Review: Journal of Management,31 (6) p.p 847-900

[9] Cropanzano, R. Bowen, D.E. \& Gilliland, S.W. (2007). The management of organizational justice. Academy of Management Perspectives. November, 34-48.

[10] De Vos, A. (2008). Research at grassroots. A primer for the caring professions. Pretoria: Van Schaik.

[11] De Cenzo, D. A. (2007) Human Relations: Personal and Professional Development; London: Prentice Hall International

[12] Dessler, G. (2004) Human Resource Management, $9^{\text {th }}$ Edition. New Dehli: Prentice Hall (India)

[13] Dzimbiri, L. (2009) Trade Unionism under the one-party and Multiparty Political Systems in Malawi, Malawi Journal of Social Science

[14] Finnemore, M. (2006). Introduction to labour relations in South Africa. Cape Town: Butterworths.

[15] Goldman, B.M. (2003). The application of reference cognitions theory to legal-claiming by terminated workers. The role of organizational justice and anger. Journal of Management, 29(5), 705-728.

[16] Gómez-Mejia, L.R.,Balkin, D.B. \&Cardy, R.L. (2005). Managing Human Resources. Englewood Cliffs, N.J: Prentice Hall.

[17] Greenberg, J. \& Baron, R.A. (2007). Behavior in organizations. Upper Saddle River, NJ: Pearson Education, Inc.

[18] Grobler, P.Warnich, S., Carrell, M.R., Elbert, N.F. \& Hatfield, R.D. (2006). Human resource management in South Africa. London: Thomson.

[19] Grossett, M. (1999). Discipline and dismissal. A practical guide for South African managers (2nd Ed.) Johannesburg: Thomson.

[20] Grogan, J. (2009).Workplace Law, tenth edition: Oxiford University Press, Grahamstown Kreitner, R. \&Kinicki, A. (2007). Organizational behavior (7th Ed.). New York: McGraw-Hill.

[21] Kvale, S. (1996). An introduction in qualitative research interviewing. Thousand Oaks, CA: Sage Publications.

[22] Latham, G.P. (2007). Work motivation: history, research, theory and practice. California: Sage Publications.

[23] Lind, E.A. \& Taylor, T.R. (2008). The Social Psychology of Procedural Justice. New York: Plenum Press Malawi Government, (1975) Malawi Public Service Regulations.

[24] Malawi Government, (1976) Public Service Commission Regulations, Government Printer, Zomba.

[25] Mathis, R and Jackson, J. A. (2008) Personnel and Human Resource Management, $5^{\text {th }}$ Edition, New York. West Publishing Company

[26] Nel, P. S. et al (2007) Human Resources Management, Oxford University Press: Capetown Noe, R.A, Hollenbeck, J., Gerhart, B. \& Wright, P.M. (2008). Human Resources Management: Gaining A Competitive Advantage, 6th Ed. McGraw Hill: New York

[27] Nova S. (2012). The Relationship between Employment Arbitration and Workplace Dispute Resolution: Ohio State Journal on Dispute Resolution 16(3): 643-668.23

[28] Pinder, C.C. (2008). Work motivation in organizational behavior. Upper Saddle River, NJ: Prentice Hall Rao, A.( 2009). Distressed Grievance procedures and their rehabilitation. Institute of industrial

[29] Relations, 5(1), p. 209.

[30] Skarlicki, D.P. \&Folger, R.Skarlicki, D.P. \&Folger, R. (1997). Retaliation in the workplace: the roles of distributive, procedural, and interactional justice. Journal of Applied Psychology, 82(3), 434- 443.

[31] Stecher, M.D. \&Rosse, J.G. (2005). The distributive side of interactional justice: the effects of interpersonal treatment on emotional arousal. Journal of Managerial Issues, 17, 229-246.

[32] Stone, J. (2005) Management Control. The Role of Discipline London: Association of Chartered and Certified Accountants Torrington, D, Hall. L \& Taylor. S (2008) 6th Edition: Human Resource Management: Essex: Prentice Hall

[33] Thompson, M. \& Heron, P. (2005). The difference a manager can make: organizational justice and knowledge worker commitment. International Journal of Human Resource Management, 16(3), 383-404.

[34] Van Der Bank, L et al (2007) Perceived Fairness of Disciplinary Procedures in the Public Sector: An exploratory study, Journal Management. Vol 6, 1-8

[35] Werner, A. (2007). Organisationalbehaviour: a contemporary South African perspective. Pretoria: Van Schaik Publishers 